\title{
28 Research Suare \\ Vpr R36w and R77Q Mutations Alter HIV-1 Replication and Cytotoxicity in T Lymphocytes
}

\section{Antonio Solis-Leal}

Brigham Young University

\section{Dalton C. Karlinsey}

Brigham Young University

\section{J. Brandon Lopez}

Brigham Young University

Vicente Planelles

The University of Utah

\section{Brian D. Poole}

Brigham Young University

Bradford Berges ( $\square$ brad.berges@gmail.com )

Brigham Young University https://orcid.org/0000-0003-0711-576X

\section{Research}

Keywords: Acquired immunodeficiency syndrome (AIDS), Rapid Progressor (RP), Long-Term NonProgressor (LTNP)

Posted Date: November 19th, 2020

DOl: https://doi.org/10.21203/rs.3.rs-107662/v1

License: (c) (1) This work is licensed under a Creative Commons Attribution 4.0 International License.

Read Full License 


\section{Abstract}

Background: Acquired immunodeficiency syndrome (AIDS) is caused when HIV depletes CD4+ helper T cell levels in infected patients. Distinct AIDS development rates have shown that there are Rapid Progressor (RP) and Long-Term Non-Progressor (LTNP) patients, but the circumstances governing these differences in the kinetics of helper $\mathrm{T}$ cell depletion are poorly understood. Mutations in the Viral Protein $\mathrm{R}$ (Vpr) gene have been suggested to have a direct impact on helper T cell depletion. Interactions of Vpr with both host and viral factors affect cellular activities such as cell cycle progression and apoptosis. The Vpr mutants R36W and R77Q have been associated with RP and LTNP phenotypes, respectively; however, these findings are still controversial. This study examines the effects that $\mathrm{Vpr}$ mutations have in the context of HIV-1 infection of the HUT78 T cell line, using replication-competent CXCR4-tropic virus strains.

Results: Our results show a replication enhancement of the R36W mutant accompanied by increased cytotoxicity. Interestingly, the R77Q mutant showed a unique enhancement of apoptosis (measured by Annexin V and TUNEL staining) and G2 cell cycle arrest; these effects were not seen with WT, R36W or Vpr null viruses. Thus, point mutations in Vpr can exhibit profound differences in mechanisms and rates of cell killing.

Conclusions: The vprgene is thought to be an important virulence factor in Human Immunodeficiency Virus type 1 (HIV-1). Vpr polymorphisms have been associated with different rates of AIDS progression. However, there is controversy about the cytopathic and virulence phenotypes of Vpr mutants, with contradictory conclusions about the same mutants. Here, we examine the replication capacity, apoptotic induction, and $\mathrm{G} 2$ cell cycle arrest phenotypes of three vprmutants compared to wild-type HIV-1. One mutant associated with rapid AIDS progression replicated more efficiently and killed cells more rapidly than wild-type HIV-1. Another mutant associated with slow AIDS progression triggered apoptosis more efficiently than wild-type HIV-1 and showed significant levels of G2 cell cycle arrest. These results shed additional light on the role of vprpolymorphisms in T cell killing by HIV-1 and may help to explain the role of $\mathrm{Vpr}$ in different rates of AIDS progression.

\section{Background}

The vprgene is found in many types of lentiviruses, including Human Immunodeficiency Virus type 1 (HIV-1), HIV-2 and Simian Immunodeficiency Virus. It has a critical role in pathogenesis and replication, and is classified as a viral regulatory protein [1,2]. The $v p r$ gene has been shown to be highly conserved across many types of lentiviruses, suggesting the biological importance of Vpr in the viral life cycle [3, 4].

Although $v p r$ is a late gene, the mature virion carries many copies of the protein inside the capsid, and thus it is active during early stages of infection $[5,6]$. Vpr carries out different functions during the viral infection cycle. It is part of the pre-integration complex, which facilitates the translocation of viral DNA to the nucleus of non-dividing cells [7]. It also likely plays a crucial role in counteracting cellular antiviral factors; this activity is highly related to its morphology and interactions with other Vpr proteins or host 
factors [8]. Furthermore, the presence of Vpr has been shown to enhance virus replication in T cells [9]. This effect could stem from several of the interactions that Vpr has with the host cell, including Vprmediated G2 phase cell cycle arrest [10-13] or through transcriptional modulation [14-17]. During G2 phase, the HIV Long Terminal Repeat promoter is more active [18], suggesting that viral-induced G2 arrest could be a tool to enhance viral replication.

One of the other functions most commonly associated with Vpr is the regulation of apoptosis in infected cells $[19,20]$. Early studies showed that Vpr can cause the permeabilization of the permeability pore complex (PTPC), resulting in the release of apoptotic factors from the mitochondrial membrane [20-22]. However, it was later shown that Vpr-induced depolarization of the mitochondrial membrane was not a result of Vpr binding to PTPC, but rather due to activation of the Bax protein, which is a result of stress signals sent by the Ataxia Telangiectasia and Rad3-related (ATR) DNA damage response pathway [23]. The ATR pathway responds to DNA damage, and when activated it initiates a signaling cascade that stalls the cell at a cycle checkpoint [24]. Activated ATR has also been shown to phosphorylate Breast Cancer type 1 susceptibility protein (BRCA1), which in turn leads to the upregulation of Growth Arrest and DNA Damage inducible alpha protein (GADD45a), which eventually leads to Bax activation and the release of apoptotic factors from mitochondria. Knocking down ATR expression with RNAi abrogated both the $\mathrm{G} 2$ arrest and apoptosis associated with Vpr expression, showing that the processes happen concomitantly [23-25]. It has been hypothesized that ATR is activated in response to Vpr-induced herniations in the nuclear membrane $[25,26]$. Despite both processes being regulated by ATR activation, Vpr induction of G2 arrest and apoptosis are independent processes [18, 27-30]. It has been observed that HIV-infected cells are more commonly apoptotic during $\mathrm{G} 1$ or S phase, while cell cycle arrest occurs in $\mathrm{M}$ or $\mathrm{G} 2$ phase $[22,27,30,31]$. Both virion-associated and de novo-synthesized Vpr are able to induce apoptosis and cell cycle arrest through identical pathways [27, 32]. Additionally, secreted Vpr has been suggested to cause apoptosis by the permeabilization of cellular membranes to calcium and magnesium [33-35]. Vpr- and reverse transcription-induced apoptosis have been shown to be the main causes of cell death in peripheral blood resting CD4+ T cells, potentially contributing to bystander cell death associated with HIV infections [36].

Acquired immunodeficiency syndrome (AIDS) is a consequence of the tropism of HIV, which targets CD4+ T cells. These cells are essential for coordinating adaptive immune responses to pathogens, but HIV infection can cause a decrease in their concentration in blood to less than $200 \mathrm{CD} 4+\mathrm{T}$ cells $/ \mathrm{mL}$ of blood, compared to about $1,000 \mathrm{CD} 4+\mathrm{T}$ cells/mL of blood in healthy individuals [37]. Patients that maintain normal levels of CD4+ T cells for many years are classified as long term non-progressors (LTNP) while those that experience a rapid decrease in $\mathrm{CD} 4+\mathrm{T}$ cells are classified as rapid progressors (RP); RP patients usually develop AIDS 5 to 8 years after infection [38]. Mutations in $v p r$ have been proposed as a causative agent of the phenotypic differences observed in infected patients [39,40], but there is much that is not understood due to the complexity of both viral and host genetics. Various mechanisms have been proposed to explain how Vpr could enhance disease progression: A) Promoting early $\mathrm{T}$ cell activation, by enhancing Nuclear Factor of Activated T cells (NFAT) to prime non-activated T cells for productive infection [41]; B) Inhibiting T cell proliferation and enhancing cell death [3]; or C) Inducing the 
infection and activation of virus production from latency in macrophages, creating drug-resistant HIV reservoirs [42-44].

The Vpr R77Q mutant has been suggested to produce a LTNP phenotype in HIV-infected patients. This mutation has been found in several LTNP patients, and has also been reported to produce low virus replication $[9,39,45]$. However, other studies have shown that this mutation does not delay AIDS progression in subjects receiving antiretroviral therapies [46, 47], increasing the controversy around the cytopathogenicity of this mutation. On the other hand, the Vpr R36W mutation has been associated with RP, but was shown to have similar replication and CD4+ T cell depletion rates to wild-type strains (WT) [9]. Vpr R36W mutants also may have an enhanced capacity to oligomerize that could impair its ability to induce $\mathrm{G} 2$ cell cycle arrest and enhance the killing of helper T cells [9].

In this study, we analyze the replication rate, G2 arrest, and apoptotic phenotypes of HUT78 cells infected with replication-competent HIV-1 expressing wild-type Vpr, or R36W, R77Q, or Vpr null mutants to better understand the role that Vpr plays in viral replication and T cell killing pathways.

\section{Results}

\section{Construction of vprmutants}

All virus strains used in this study were based on the wild-type (WT) pNL4-3 molecular clone, which uses CXRC4 as a co-receptor. The R36W and R77Q constructs were produced by replacing the WT vpr gene with mutated vprsequences from expression plasmids obtained from Dr. Velpandi Ayyavoo [9]. We created the Vpr null mutant to study the effects of HIV infection with a defective vprgene but without any mutations in neighboring genes/reading frames. This was accomplished using site-directed mutagenesis (SDM) to mutate the vprstart codon (ATG to GTG, or M1V), resulting in a silent mutation in nucleotide 173 of the overlapping vif gene (AGA to AGG; both encode arginine). Figure 1A shows the differences in nucleotide sequences between each strain and the corresponding change in amino acid sequence. Sanger DNA sequencing was used to confirm the desired mutations and to show that no additional mutations were introduced during the creation of constructs (data not shown).

To confirm the expression of Vpr in WT, R36W and R77Q mutants, and the lack of expression in the null mutant, we detected Vpr expression via immunoblotting of infected cell lysates. Infected HUT78 cell lysates (a human CD4+ T cell line) collected at 7dpi at $\mathrm{MOI} 0.01$ were used (this time point was chosen because viral genome levels were most similar; see Fig 2A). HUT78 cells were derived from a cutaneous T cell lymphoma, and represent a mature CD4+ helper T cell line that supports HIV-1 infection [48]. We found that WT virus as well as the R36W and R77Q mutants produced detectable Vpr, while no Vpr was detected in the null mutant or in uninfected cells (Fig. 1B). Vpr expression from the R77Q mutant was consistently found at reduced levels compared to the WT and R36W.

\section{The R36W mutant has an enhanced replication capacity relative to WT virus}


To examine the replicative capacity of our mutants in a T cell line, HUT78 cells infected at $0.01 \mathrm{MOI}$ were analyzed for viral replication via Q-RT-PCR over a 21-day period post-infection. We observed significant differences in virus replication levels amongst the various strains used within the first $7 \mathrm{dpi}$, but similar values thereafter, thus we focused our analyses on the first 7 days (Figure 2A). After 3 days, the only statistically significant difference in genome copy number that we observed was between the R77Q and WT populations. The R77Q infected population had a viral load of $1.0 \times 10^{8} \mathrm{RNA}$ copies $/ \mathrm{mL}$, which was almost ten-fold higher than the load of the WT virus $\left(1.7 \times 10^{7}\right.$ copies $\left./ \mathrm{mL}\right)$, but at 5 and 7 days postinfection (dpi), there was no difference between these populations. The R36W-infected population had a ten-fold higher load $\left(2.9 \times 10^{9} \mathrm{copies} / \mathrm{mL}\right)$ that was significant compared to all other strains at $5 \mathrm{dpi}$. While still statistically significant at $7 \mathrm{dpi}$, the difference between R36W and the other strains was considerably smaller (Figure 2A). There was no significant difference in viral load between the WT, R77Q, and null viruses at either 5 or $7 \mathrm{dpi}$ (Data Set S1).

Each mutant's capacity to spread through the culture was studied by measuring the p24 expression of individual cells through flow cytometry (Figure 2B/2C). Cells infected with the R36W mutant showed a significantly increased p24+ population at all three time points compared to the WT and null viruses (Data set S2). R36W also had much higher p24 expression than R77Q at 3 and $5 \mathrm{dpi}$, but on day 7, both populations were about $80 \% \mathrm{p} 24+$. Mean fluorescent intensity (MFI) of p24+ histograms were also examined and showed that p24 production in individual cells was also significantly higher following infection with the R36W mutant as compared to all other virus strains (Data Set S3), indicating that viral gene expression was also higher in cells infected with the R36W mutant.

\section{Infection with R77Q mutant leads to an increase in apoptosis}

To test whether the Vpr mutants induced differing levels of apoptosis, we infected HUT78 cells at 0.01 $\mathrm{MOI}$ and stained with Annexin $\mathrm{V}$ and Fixable Viability Dye (FVD) and analyzed the results via flow cytometry. Annexin $V$ binds to phosphatidylserine, which flips from the inner layer of the plasma membrane to the outer layer during the early stages of apoptosis [49]. Cells were also stained with FVD, which enters cells through porous plasma membranes and indiscriminately binds proteins. Since cells with a permeabilized membrane will also allow Annexin $V$ staining due to the antibody finding phosphatidylserine inside the plasma membrane, we considered cells positive for both FVD and Annexin $\mathrm{V}$ as dead while cells positive for Annexin $\mathrm{V}$ only were considered to be apoptotic.

The results of this assay (Figure 3) showed a clear difference in levels of apoptotic induction by the R77Q mutant. At all three time points, the R77Q-infected population had significantly higher levels of apoptosis; at $7 \mathrm{dpi}$, the R77Q population had a mean level of $47.4 \%$ Annexin $V$ single-positive cells, compared to $2.64 \%$ in WT, 5.54\% in R36W, 7.26\% in null, and 3.29\% in the uninfected population (Figure 3A/3B). The only significant difference in the number of apoptotic cells in the WT and R36W populations was $7 \mathrm{dpi}$; on days 3 and 5, the two populations had similar numbers of apoptotic cells (Data Set S4B). The null population also had a significant increase in the number of apoptotic cells $(7.26 \%)$ at $7 \mathrm{dpi}$ compared to the WT population. The null population had similar numbers of apoptotic cells to R36W at both 3 and 7 
dpi, but interestingly had a significantly $(p=0.021)$ lower number of apoptotic cells as compared to R36W when observed at 5 dpi (Data Set S4B). The number of apoptotic cells in the WT population was not significantly different from the uninfected population at all three time points.

We also observed clear differences in the number of dead cells in each population, as defined by porous plasma membranes. Apoptotic cell death does not result in plasma membrane disruption, while necrotic death pathways do show a loss of plasma membrane integrity. At $7 \mathrm{dpi}$, all four infected populations had significantly higher numbers of dead cells than the uninfected control (Figure 3C, Data Set S4A). The percentage of dead cells in the R36W- and WT-infected populations was significantly higher than in the R77Q and null populations. At both 5 and $7 \mathrm{dpi}$, there was a significant difference between the R36W and WT populations. At both time points, the number of dead cells in the R36W population was twice as high as in the WT population (Figure 3A/3C). The percentage of dead cells in the null-infected population was significantly smaller than the other infected populations; it had relatively similar levels of apoptosis to the WT but fewer overall dead cells. The lack of an FVD (-), Annexin V (+) population in our results (Figure 3A) suggests that the WT and R36W mutants either induce extremely rapid apoptosis, or that they preferentially activate a necrotic pathway to kill cells. These data suggest that the R36W and R77Q mutants are significantly more cytopathic than the WT virus, but that they cause cell death via different pathways relative to each other. The CEM and SUP-T1 human T cell lines were infected in similar fashion and analyzed for the apoptotic phenotype observed in HUT78 cells. Interestingly, neither of these cell lines showed apoptotic induction following R77Q infection that was different than that seen with WT, R36W, null, or uninfected cells (Data not shown).

\section{TUNEL staining confirms that the R77Q mutant induces apoptosis}

To confirm that the double-positive dead cells observed in the Annexin V staining (Figure 3A) had not simply undergone apoptosis more rapidly, infected cells were stained for DNA fragmentation, a classical sign of late-stage apoptosis [49]. TUNEL (terminal deoxynucleotidyl transferase-dUTP nick end labeling) analysis by flow cytometry showed minimal signs of DNA fragmentation in the uninfected, WT, R36W, and null mutant infected populations at both 5 and $7 \mathrm{dpi}$, while the R77Q-infected population had a significantly increased percentage of apoptotic cells (Figure 4A/4B, Data Set S5). At 7 dpi, the R77Qinfected population was $8.34 \%$ positive for TUNEL, while all the other populations had minimal TUNEL+ cells. Figures 4C/4D show a comparison of our apoptosis results as detected by either Annexin $\mathrm{V}$ or TUNEL staining. The R77Q mutant showed a significantly higher proportion of cells with apoptotic markers on days 5 and 7 compared to all other samples, as detected by each assay. The percentage of R77Q-infected cells positive for Annexin V was higher than the percentage of cells positive for TUNEL at days 5 and 7. This may be due to the fact that phosphatidylserine exposure occurs earlier during the apoptotic process than does DNA fragmentation [49], allowing a greater number of Annexin V-positive cells to be detected if many cells have not yet progressed to late apoptosis. Together these data show that the R77Q mutant primarily kills cells through the induction of apoptosis, while the WT, R36W, and null viruses cause death through different, non-apoptotic pathways. 


\section{G2 cell cycle arrest is most prominent in cells infected with the R77Q mutant}

To determine if these mutants differed in their capacity to arrest cells in G2 phase, we used flow cytometry to observe the cell cycle progression of infected cells. HUT78 cells were infected with $0.1 \mathrm{MOI}$, then at $7 \mathrm{dpi}$ cells were stained with propidium iodide and with antibodies to the p24 antigen and analyzed through flow cytometry. p24+ populations were gated to study cell cycle arrest specifically in infected cells. Only results from $7 \mathrm{dpi}$ are reported due to a need for large numbers of p24+ cells for the analysis. Figure 5 shows a significant mean increase in detection of cells in $\mathrm{G} 2$ phase in most infected samples (WT $=26.0 \%, p=0.01 ; R 77 Q=40.4 \%, p=0.01 ;$ null $=26.0 \%, p=0.03$ ) compared to the uninfected control (19.2\%) (Data Set S6). R77Q showed the highest percentage of cells arrested in G2, which was significantly higher than the other infected samples (vs WT $p=0.02$, vs R36W $p=0.04$, vs null $p=0.01$ ). R36W G2 arrest was lower than the WT and not significantly different than uninfected. A summary of the raw data, including an analysis of G1 and S phase populations is found in Supplementary Data Set S7. These results support studies that show that the R77Q mutant enhances cell cycle arrest and that R36W has a decreased capacity to cause cell cycle arrest [9]. An analysis was also performed of p24- cells, but there was no significant difference between WT Vpr and the three mutants, or any infected cell samples compared to uninfected controls (data not shown).

\section{Discussion}

In our efforts to study the phenotypes of the R36W and R77Q Vpr mutants to gain a better understanding of the role that HIV Vpr plays in the death of helper T cells we have made four main conclusions: 1) The R36W Vpr mutation enhances the replicative capacity of HIV in HUT78 cells; 2) The R77Q Vpr mutation enhances the pro-apoptotic activity of HIV; 3) The WT, R36W and null viruses kill host cells via a necrotic, non-apoptotic pathway; and 4) The R77Q Vpr mutation enhances G2 cell cycle arrest.

We noticed several interesting differences in apoptosis induction and cell cycle arrest with the R77Q mutant as compared to WT virus or the R36W and Vpr null mutants. We also detected a very noticeable reduction in the detection of Vpr protein in R77Q-infected samples as compared to WT and R36W viruses by immunoblotting (Fig 1B). This decreased level of Vpr from the R77Q virus was consistently detected with different $\mathrm{MOI}$, and should not be due to a change in antibody interaction because the polyclonal antibody used was generated against the first 50 amino acids of $\mathrm{Vpr}$. Thus, we wondered if the apoptotic and cell cycle arrest phenotypes could be explained by a simple lack of Vpr expression. However, our use of the Vpr null mutant, which never showed detectable Vpr expression by immunoblotting (Fig 1B), failed to show either the apoptotic or the cell cycle arrest phenotypes. We increased the MOI of Vpr null infections to see if the apoptotic phenotype could be detected under varying experimental conditions, but increased apoptosis was never seen with that mutant. Thus, decreased Vpr expression alone cannot explain the correlation between low or non-existent Vpr expression and the phenotypes observed. It is possible that low levels of Vpr expression give a different phenotype as compared to high expression or complete lack of expression; our experiments did not address this possibility. 
We examined two other human T cell lines (CEM and SUP-T1) for the apoptotic phenotype by Annexin V and FVD staining, but we failed to observe any increase in apoptosis upon infecting these other cell lines with the R77Q mutant. While the meaning for these findings is still unclear, it suggests that something in the genotype of HUT78 cells may be different as compared to the other cell lines. This finding is not entirely unexpected, since host genetics plus viral genetics are both thought to play a role in AIDS progression. A future analysis of genes present or absent in HUT78 vs CEM and SUP-T1 cells, or an analysis of gene expression profiles of the two cell types, may shed additional light on this area.

In our analysis of replication capacity by Q-RT-PCR of viral load and measurement of p24 expression via flow cytometry, we found that R36W-infected cells produced significantly more virus, and more p24+ cells compared to other strains. Interestingly, our findings show that both the R77Q and the null mutants behaved very similarly to the WT virus in terms of viral replication rates, suggesting that these mutations do not impact viral replication efficiency in an in vitro setting. The mechanism by which the R36W mutant replicates more effectively in helper T cells is still to be determined. However, our findings have implications for the RP phenotype in that the R36W virus replicates better and spreads to new cells more effectively than WT virus, which would be expected for a virus associated with faster than normal AIDS progression.

There was not a significant increase in the number of viral genome copies or p24+ cells in the R36Winfected population from days 5 to 7 . This may be because the R36W-infected population had reached a plateau in terms of both HIV production and cell infection due to the limited number of infectable cells in the culture. As a result, the differences in the replication kinetics of each mutant were most visible at 5 dpi, and by $7 \mathrm{dpi}$ the other mutants produced a more similar viral load. Overall, these results show that R36W has a significantly higher replication and infection capacity compared to the WT virus. A previous study by Hadi et al. reported that WT virus showed the highest replication levels, followed by R36W (among other mutants studied) and that the R77Q mutant replicated at levels seven-fold lower than the WT virus [9]. However, Hadi et al. constructed their mutants using a modified strain of HIV-1 NL4-3 engineered to express the EGFP reporter that places Nef expression under the control of an IRES element, which could result in virus attenuation [50]. Therefore, cells infected with that virus strain may show different behavior than that observed with normal Nef expression from unmanipulated HIV-1 NL4-3. Much of the controversy regarding Vpr function is likely a result of the many different experimental systems used to study its effects including primary cells, cells in a three-dimensional lymphoid tissue, and cell lines. The Hadi et al study was conducted in primary cells, which could potentially vary in activation status and influence the replication kinetics of the different viruses. Our use of a clonal population eliminates this variable.

The R77Q mutant showed significantly higher levels of G2 cell cycle arrest compared to WT virus and the other two mutants. Since the LTR promoter is known to be most active during G2 phase [51], but the R36W mutant was the strain that replicated the best, these results appear to be conflicting. Our p24 MFI results showed the highest levels of p24 expression levels at day 7 for R77Q (significantly different than WT, $p=0.02$ and Null, $p=0.008$ ), but not significantly different than R36W, $p=0.16$; See Data Set S3), which 
may support enhancement of viral gene expression due to LTR activation. Our viral load and p24 expression results show that the R36W virus still replicates significantly better in HUT78 cells, suggesting that the R36W mutation provides a stronger effect on viral replication than the $\mathrm{G} 2$ arrest observed in R77Q infections.

A potential difference in these mutants that could affect cell killing rates is their distinct mechanisms of causing cell death. Contrary to the results of previous studies [23,39], we observed much higher rates of apoptosis in the R77Q-infected population as compared to either the WT or the other mutant populations. The difference between our observed R77Q apoptosis phenotype and those previously reported is also likely a result of different experimental systems. The previous data that associated R77Q Vpr with a normal or decreased capacity for apoptosis was observed in HeLa cells transduced with R77Q Vprexpressing plasmids [23] or in Jurkat cells infected with VSV-G pseudotyped virus [39]. Our experimental system most closely resembles the natural conditions of infection since we have studied Vpr function in the context of replication-competent HIV, including the apoptotic functions previously ascribed to vif, env, etc. [52, 53]. As a cancer cell line, HUT78 cells are relatively resistant to apoptosis; this resistance is a result of null mutations in the $p 53$ gene $[48,54]$. However, since Vpr-induced apoptosis is $p 53-$

independent $[25,55]$, we believe that R77Q Vpr is a bona fide pro-apoptotic mutation while WT and R36W Vpr induce necrotic cell death.

HIV and Vpr have been shown to induce pyroptosis in bystander cells [56], but this process is mediated by cell-to-cell contact [57], primarily within three-dimensional lymphoid tissue models and not in peripheral blood cells $[36,58]$. Therefore, it is unlikely that the form of necrotic cell death observed in our suspension of T cells was pyroptosis [48]. An apoptosis-independent form of HIV-1-mediated cell death has been previously reported $[59,60]$. More recently, necroptosis, a form of programmed necrotic cell death was shown to take place in HIV-1 infected cells by Pan et al. [61]. Due to similarities between our data and the data reported by Pan et al., we believe that the necrotic cell death observed in the WT, R36W, and Null populations was likely a result of necroptosis. The mechanism by which HIV-1 induces necroptosis is still unknown, but it may be via a combination of host and viral factors and not directly induced by a specific viral protein [61]. It is interesting to note however, that Pan et al. reported an inverse relationship between the levels of apoptosis and necroptosis in infected populations of cells, suggesting that the pathways serve as alternatives to one another. Mutations like R77Q that lead to a preference of one pathway over another could have a significant impact on host-virus interactions.

\section{Conclusion}

In vivo, a tendency to induce pro-inflammatory death could potentially lead to a faster and/or more potent chronic activation of the immune system, which has been hypothesized to lead to AIDS progression [62]. Thus, the R36W mutation could show an RP phenotype based upon the avoidance of apoptosis and reliance on necrotic death mechanisms, which are highly inflammatory [63]. This mechanism would fit in well with the RP phenotype reported by others [9]. On the other hand, it is known that apoptosis does not enhance a systemic inflammation [64] and therefore could delay the chronic activation of the immune 
system that leads to AIDS. If the R77Q mutation influences host cells to die primarily by apoptosis, this could potentially explain the LTNP phenotype associated with it. Although R77Q is highly cytotoxic and replicates at a similar rate to the WT virus, the death pathway followed by infected cells could significantly alter the host's immune response during chronic HIV-1 infection. Only an in vivo study, however, will be able to conclusively determine the progression phenotypes of the R36W and R77Q mutations in a more physiological setting.

In summary, we present novel replication and cytopathic phenotypes associated with the R36W and R77Q Vpr mutations that could potentially contribute to the overall role that HIV Vpr plays in CD4+ T cell depletion.

\section{Methods}

\section{Plasmids}

HIV-1 pNL4-3 was obtained through the NIH AIDS Reagent Program, Division of AIDS, NIAID, NIH: HIV-1 NL4-3 Infectious Molecular Clone (pNL4-3) from Dr. Malcolm Martin (Cat\# 114)[65-67]. HIV-1 NL4-3 R36W Vpr and HIV-1 NL4-3 R77Q Vpr mutants were a gift from Dr. Velpandi Ayyavoo (University of Pittsburgh). The region surrounding the vprgene was cloned into the pUC19 vector (Addgene \#50005) using the EcoRI and Sbfl sites (New England Biolabs) for site-directed mutagenesis (SDM). SDM was accomplished using back to back primers with single point mismatches to change the ATG codon to GTG for the null mutant in order to not affect any overlapping genes in the viral genome (Forward: CAGAGGACAGGTGGAACAAGC; Reverse: TCAGTTTCCTAACACTAGGC). After SDM the vprgene was removed from pUC19 using the same enzymes and ligated back into its original frame in the pNL4-3 vector. The desired mutation and in-frame ligations were confirmed by Sanger sequencing (data not shown). One shot Stbl3 E. coli cells (Invitrogen C737303) were used for transformations to avoid plasmid recombination.

\section{Cell culture}

HEK293FT cells were maintained at $37^{\circ} \mathrm{C}, 5 \% \mathrm{CO}_{2}$ in DMEM (Sigma-Aldrich) supplemented with $10 \%$ fetal bovine serum (FBS; HyClone), 2\% glutamine, 1\% G418 (Teknova) and 1\% penicillin/streptomycin (P/S). HUT78 cells, CEM cells and SUPT1 cells were maintained at $37^{\circ} \mathrm{C}, 5 \% \mathrm{CO} 2$ in RPMI (Mediatech) supplemented with $10 \% \mathrm{FBS}, 1 \%$ glutamine and $1 \% \mathrm{P} / \mathrm{S}$. Ghost R3/X4/R5 cells were maintained at $37^{\circ} \mathrm{C}$, $5 \%$ CO2 in DMEM, supplemented with $10 \% \mathrm{FBS}, 1 \% \mathrm{P} / \mathrm{S}, 500 \mathrm{mg} / \mathrm{mL} \mathrm{G} 418,100 \mathrm{mg} / \mathrm{mL}$ hygromycin, and $1 \mathrm{mg} / \mathrm{mL}$ puromycin. (Ghost cells were obtained through the NIH AIDS Reagent Program, Division of AIDS, NIAID, NIH: GHOST (3) CCR3+ CXCR4+ CCR5+ Cells from Dr. Vineet N. KewalRamani and Dr. Dan R. Littman (cat\# 3943)[68]).

\section{Transfection and viral titration}


HEK293FT cells were transfected using the calcium phosphate method; virus was collected 48 hours post-transfection. Viral concentration was determined by titration using Ghost R3/X4/R5 cell line using the methods described at the NIH AIDS Reagent Program [69].

\section{HIV-1 infections and flow cytometry analysis}

Cells were infected with $0.1 \mathrm{MOI}$ (cell cycle analysis) or $0.01 \mathrm{MOI}$ (all other experiments) with polybrene. Cells were collected on the specified day of infection for each test and prepared as follows for Annexin $V$ flow cytometry analysis. Cells were washed twice with serum-free PBS and centrifuged for 5 minutes at $500 \mathrm{x}$ g, stained with Fixable Viability Dye (FVD) for 30 minutes at $4^{\circ} \mathrm{C}$, and then washed with FACS staining buffer (FCSB) (140mM NaCl, 4mM KCl, $\left.0.75 \mathrm{mM} \mathrm{MgCl}_{2}, 10 \mathrm{mM} \mathrm{HEPES,} 1 \% \mathrm{BSA}, 0.1 \% \mathrm{NaN}_{3}\right)$, $\mathrm{CaCl}_{2}$ was then added at a concentration of $1.5 \mathrm{mM}$ for $10 \mathrm{~min}$ before staining with fluorochromeconjugated Annexin $V$ for $15 \mathrm{~m}$ at $25^{\circ} \mathrm{C}$. Cells were then washed with FCSB and $1.5 \mathrm{mM} \mathrm{CaCl}_{2}$, fixed with Solution $\mathrm{A}$ and $1.5 \mathrm{mM} \mathrm{CaCl}_{2}$ for 30 minutes, washed with FCSB and permeabilized with Solution B (Fix \& Perm, Nordic MUbio, GAS-002). Anti-p24 antibody was added at a final dilution of 1:400, and cells were incubated for $15 \mathrm{~m}$ at $25^{\circ} \mathrm{C}$. Cells were then washed twice with FCSB, resuspended, and analyzed by flow cytometry using a Beckman Coulter Cytoflex Cytometer [70, 71]. Results were analyzed using FlowJo software (version 10.6.2). The dyes used were: KC57 anti-HIV-1 core antigen-PE (Beckman coulter C0604667), Live/Dead fixable Far Red Dead Cell Stain Kit (Invitrogen L10120) and Annexin V FITC conjugate (Invitrogen A13199). For cell cycle analysis we used the FxCycle PI/ RNase Staining Solution (Invitrogen F10797) together with KC57 anti-HIV-1 core antigen-FITC (obtained through the NIH AIDS Reagent Program, Division of AIDS, NIAID, NIH: Anti-HIV-1 p24 Monoclonal (KC57)-FITC from NIAID, DAIDS (cat\# 13450)). For TUNEL assays, cells were stained with FVD, and then stained for TUNEL analysis using FragEL ${ }^{\mathrm{TM}}$ DNA Fragmentation Kit, Fluorescent-TdT Enzyme (Millipore QIA39) following the manufacturer's protocol.

\section{Immunoblotting}

HUT78 cells were washed with ice-cold PBS and lysed in RIPA buffer (ThermoFisher) with protease inhibitor cocktail (ThermoFisher). Proteins were quantified using BSA Protein Assay Kit (ThermoFisher). Equal amounts of protein were boiled with 6 X loading buffer (375mM Tris HCL, 9\% SDS, 50\% Glycerol, $0.03 \%$ Bromophenol blue) for 5 minutes. Samples were run through a $4-15 \%$ gradient polyacrylamide gel and then transferred to a PVDF membrane (BioRad). The membrane was blocked with PBS containing $5 \%$ non-fat milk for $1 \mathrm{~h}$ at $25^{\circ} \mathrm{C}$. Vpr was probed using Anti-HIV-1 Vpr polyclonal (diluted 1:3,000) (The following reagent was obtained through the NIH AIDS Reagent Program, Division of AIDS, NIAID, NIH: Cat\#11836, Anti-HIV-1 Vpr 1-50 aa Polyclonal from Dr. Jeffrey Kopp). GAPDH was probed using Rabbit anti-GAPDH (diluted 1:3,000) (Cell Signaling Technology). Both antibodies were detected using Goat antiRabbit HRP-conjugated (1:15,000) (Abcam \#ab6721) antibodies. Detection was done using WesternBright ECL (Advansta) and results were analyzed using ImageJ software.

\section{Viral replication}


Viral supernatants were collected on days 3,5 and 7, and viral RNA was extracted using Viral Nucleic Acid Extraction kit II (Scientific FF10616-GB). The extracted RNA was used as template to produce cDNA using High Capacity cDNA Reverse Transcription Kit (Applied Biosystems 4368814) and LTR-specific primers. Finally, 2X Forget-Me-Not Universal Probe Master Mix with ROX (Biotium 31044-1) was used to perform QRT-PCR in an Applied Biosystems StepOnePlus ${ }^{\text {TM }}$ Real-Time PCR System Thermal Cycling Block, following the protocol described previously by Rouet et al [72]. The software used to analyze the data was StepOnePlus Software 2.2.3.Ink and results were normalized to RNA copies $\mathrm{x} \mathrm{mL}^{-1}$.

\section{Statistical analysis}

Biological samples were analyzed in triplicate using one-tailed Student's t-test with a significance level of $\mathrm{p} \leq 0.05$.

\section{Declarations}

\section{Ethics approval and consent to participate}

Not applicable.

\section{Consent for publication}

Not applicable.

\section{Availability of data and material}

All data generated or analyzed during this study are included in this published article

\section{Competing interests}

We have no competing interests to declare.

\section{Funding}

No specific funding source was used to support this project.

\section{Authors' contributions}

BKB, ASL, and DCK conceptualized and designed the study; ASL, DCK, and JBL performed all experiments; ASL, DCK and BKB performed data analysis. ASL performed viral load experiments, ASL and DCK performed all flow cytometry experiments, and JBL performed immunoblots. ASL, DCK, and JBL participated in writing the initial draft. BKB, VP, and BDP assisted with troubleshooting, experimental planning, and editing of the manuscript. All authors have approved of this version of the manuscript.

\section{Acknowledgments}


We would like to acknowledge Evelyn Wong for help with immunoblotting procedures, and Preston Neff and Brent Palmer for assistance with flow cytometry protocols.

\section{References}

1. Cohen E. A., Dehni G., Sodroski J. G., Haseltine W. A.: Human immunodeficiency virus vpr product is a virion-associated regulatory protein.Journal of virology 1990, 64:3097-3099.

2. Majumder B., Venkatachari N. J., Srinivasan A., Ayyavoo, V.: HIV-1 mediated immune pathogenesis: spotlight on the role of viral protein $\mathbf{R}$ (Vpr). Current HIV research 2009, 7:169-177.

3. Stivahtis G.L., Soares M.A., Vodicka M.A., Hahn B.H., Emerman M.: Conservation and host specificity of Vpr-mediated cell cycle arrest suggest a fundamental role in primate lentivirus evolution and biology.Journal of virology 1997, 71:4331-4338.

4. Tristem M., Marshall C., Karpas A., Hill F.: Evolution of the primate lentiviruses: Evidence from Vpx and Vpr.EMBO Journal 1992, 11:3405-3412.

5. Hrimech M, Yao XJ, Bachand F, Rougeau N, Cohen EA.: Human immunodeficiency virus type 1 (HIV1) Vpr functions as an immediate-early protein during HIV-1 infection.Journal of virology 1999, 73:4101-4109.

6. Poon B, Chen IS: Human immunodeficiency virus type 1 (HIV-1) Vpr enhances expression from unintegrated HIV-1 DNA.Journal of virology 2003, 77:3962-3972.

7. Zhao LJ, Zhu H.: Structure and function of HIV-1 auxiliary regulatory protein Vpr: novel clues to drug design. Current drug targets Immune, endocrine and metabolic disorders 2004, 4:265-275.

8. Yan N., Chen Z.J.: Intrinsic antiviral immunity.Nature Immunology 2012, 13:214-222.

9. Hadi K, Walker LA, Guha D, Murali R, Watkins SC, Tarwater P, Srinivasan A, Ayyavoo V.: Human immunodeficiency virus type $1 \mathrm{Vpr}$ polymorphisms associated with progressor and nonprogressor individuals alter Vpr-associated functions. The journal of general virology 2014, 95:700-711.

10. Rogel ME, Wu LI, Emerman M.: The human immunodeficiency virus type 1 vpr gene prevents cell proliferation during chronic infection.Journal of virology 1995, 69:882-888.

11. J He, S Choe, R Walker, P Di Marzio, D O Morgan, and N R Landau: Human immunodeficiency virus type 1 viral protein $\mathrm{R}(\mathrm{Vpr})$ arrests cells in the $\mathrm{G} 2$ phase of the cell cycle by inhibiting p34cdc2 activity.Journal of virology 1995, 69:6705-6711.

12. J B Jowett, V Planelles, B Poon, N P Shah, M L Chen, and I S Chen: The human immunodeficiency virus type $1 \mathrm{vpr}$ gene arrests infected T cells in the $\mathbf{G} 2+\mathrm{M}$ phase of the cell cycle.Journal of virology 1995, 69:6304-6313.

13. Re F, Braaten D, Franke EK, Luban J.: Human immunodeficiency virus type 1 Vpr arrests the cell cycle in $\mathbf{G} 2$ by inhibiting the activation of p34cdc2-cyclin B.Journal of virology 1995, 69:6859-6864.

14. Sawaya BE, Khalili K, Mercer WE, Denisova L, Amini S: Cooperative actions of HIV-1 Vpr and p53 modulate viral gene transcription.J Biol Chem 1998, 273:20052-20057. 
15. Sawaya BE, Khalili K, Rappaport J, Serio D, Chen W, Srinivasan A, Amini S: Suppression of HIV-1 transcription and replication by a Vpr mutant.Gene Ther 1999, 6:947-950.

16. Agostini I, Navarro JM, Rey F, Bouhamdan M, Spire B, Vigne R, Sire J: The human immunodeficiency virus type $1 \mathrm{Vpr}$ transactivator: cooperation with promoter-bound activator domains and binding to TFIIB.J Mol Biol 1996, 261:599-606.

17. Wang L, Mukherjee S, Jia F, Narayan O, Zhao LJ: Interaction of virion protein Vpr of human immunodeficiency virus type 1 with cellular transcription factor Sp1 and trans-activation of viral long terminal repeat.J Biol Chem 1995, 270:25564-25569.

18. Goh WC, Rogel ME, Kinsey CM, Michael SF, Fultz PN, Nowak MA, Hahn BH, Emerman M.: HIV-1 Vpr increases viral expression by manipulation of the cell cycle: a mechanism for selection of $\mathrm{Vpr}$ in vivo.Nature medicine 1998, 4:65-71.

19. Ayyavoo V, Mahboubi A, Mahalingam S, Ramalingam R, Kudchodkar S, Williams WV, Green DR, Weiner DB: HIV-1 Vpr suppresses immune activation and apoptosis through regulation of nuclear factor kappa B.Nat Med 1997, 3:1117-1123.

20. Jacotot E, Ravagnan L, Loeffler M, Ferri KF, Vieira HL, Zamzami N, Costantini P, Druillennec S, Hoebeke J, Briand JP, et al: The HIV-1 viral protein R induces apoptosis via a direct effect on the mitochondrial permeability transition pore.J Exp Med 2000, 191:33-46.

21. Jacotot E, Ravagnan L, Loeffler M, Ferri KF, Vieira HL, Zamzami N, Costantini P, Druillennec S, Hoebeke J, Briand JP, Irinopoulou T, Daugas E, Susin SA, Cointe D, Xie ZH, Reed JC, Roques BP, Kroemer G.: The HIV-1 viral protein R induces apoptosis via a direct effect on the mitochondrial permeability transition pore. The journal of experimental medicine 2000, 191:33-46.

22. ME G: The HIV-1 Vpr Protein: A Multifaceted Target for Therapeutic Intervention.International journal of molecular science $2017,18$.

23. Andersen JL, DeHart JL, Zimmerman ES, Ardon O, Kim B, Jacquot G, Benichou S, Planelles V: HIV-1 Vpr-induced apoptosis is cell cycle dependent and requires Bax but not ANT.PLoS Pathog 2006, 2:e127.

24. Roshal M, Kim B, Zhu Y, Nghiem P, Planelles V: Activation of the ATR-mediated DNA damage response by the HIV-1 viral protein R.J Biol Chem 2003, 278:25879-25886.

25. Andersen JL, Zimmerman ES, DeHart JL, Murala S, Ardon O, Blackett J, Chen J, Planelles V: ATR and GADD45alpha mediate HIV-1 Vpr-induced apoptosis.Cell Death Differ 2005, 12:326-334.

26. de Noronha CM, Sherman MP, Lin HW, Cavrois MV, Moir RD, Goldman RD, Greene WC: Dynamic disruptions in nuclear envelope architecture and integrity induced by HIV-1 Vpr.Science 2001, 294:1105-1108.

27. Murakami T, Aida Y: Visualizing Vpr-induced G2 arrest and apoptosis.PLoS One 2014, 9:e86840.

28. Stewart SA, Poon B, Jowett JB, Chen IS: Human immunodeficiency virus type 1 Vpr induces apoptosis following cell cycle arrest.J Virol 1997, 71:5579-5592.

29. Nishizawa M, Kamata M, Mojin T, Nakai Y, Aida Y: Induction of apoptosis by the Vpr protein of human immunodeficiency virus type 1 occurs independently of $\mathrm{G}(2)$ arrest of the cell cycle.Virology 
2000, 276:16-26.

30. Bolton DL, Lenardo MJ.: Vpr cytopathicity independent of G2/M cell cycle arrest in human immunodeficiency virus type 1-infected CD4+ T cells.Journal of virology 2007, 81:8878-8890.

31. Stromájer-Rácz T, Gazdag Z, Belágyi J, Vágvölgyi C, Zhao RY, Pesti M.: Oxidative stress induced by HIV-1 F34IVpr in Schizosaccharomyces pombe is one of its multiple functions. Experimental and molecular pathology 2010, 88:38-44.

32. Arokium H, Kamata M, Chen I: Virion-associated Vpr of human immunodeficiency virus type 1 triggers activation of apoptotic events and enhances fas-induced apoptosis in human T cells.J Virol 2009, 83:11283-11297.

33. Levy DN, Refaeli Y, Weiner DB.: Extracellular Vpr protein increases cellular permissiveness to human immunodeficiency virus replication and reactivates virus from latency.Journal of virology 1995, 69:1243-1252.

34. Aukrust P, Liabakk NB, Müller F, Lien E, Espevik T, Frøland SS.: Serum levels of tumor necrosis factoralpha (TNF alpha) and soluble TNF receptors in human immunodeficiency virus type 1 infectioncorrelations to clinical, immunologic, and virologic parameters. The Journal of infectious disease 1994, 169:420-424.

35. Macreadie IG, Arunagiri CK, Hewish DR, White JF, Azad AA.: Extracellular addition of a domain of HIV$1 \mathrm{Vpr}$ containing the amino acid sequence motif $\mathrm{H}(\mathrm{S} / \mathrm{F}) \mathrm{RIG}$ causes cell membrane permeabilization and death.Molecular microbiology 1996:1185-1192.

36. Trinite B, Chan CN, Lee CS, Levy DN: HIV-1 Vpr-and Reverse Transcription-Induced Apoptosis in Resting Peripheral Blood CD4 T Cells and Protection by Common Gamma-Chain Cytokines.J Virol 2016, 90:904-916.

37. Naif HM: Pathogenesis of HIV Infection.Infectious Disease Reports 2013, 5(Suppl 1):e6.

38. Shioda T, Nakayama EE: Human genetic polymorphisms affecting HIV-1 diseases.International journal of hematology 2006, 84:12-17.

39. Lum JJ, Cohen OJ, Nie Z, Weaver JG, Gomez TS, Yao XJ, Lynch D, Pilon AA, Hawley N, Kim JE, Chen Z, Montpetit M, Sanchez-Dardon J, Cohen EA, Badley AD.: Vpr R77Q is associated with long-term nonprogressive HIV infection and impaired induction of apoptosis. The Journal of clinical investigation 2003, 111:1547-1554.

40. Rodés B, Toro C, Paxinos E, Poveda E, Martinez-Padial M, Benito JM, Jimenez V, Wrin T, Bassani S, Soriano $\mathrm{V}$.: Differences in disease progression in a cohort of long-term non-progressors after more than 16 years of HIV-1 infection.AIDS 2004, 18:1109-1106.

41. Höhne K, Businger R, van Nuffel A, Bolduan S, Koppensteiner H, Baeyens A, Vermeire J, Malatinkova E, Verhasselt B, Schindler M: Virion encapsidated HIV-1 Vpr induces NFAT to prime non-activated T cells for productive infection.Open biology 2016, doi: 10.1098/rsob.160046.

42. Levy DN, Refaeli Y, MacGregor RR, Weiner DB.: Serum Vpr regulates productive infection and latency of human immunodeficiency virus type 1.Proc Natl Acad Sci U S A 1994, 91:10873-10877. 
43. Cohen EA, Terwilliger EF, Jalinoos Y, Proulx J, Sodroski JG, Haseltine WA.: Identification of HIV-1 vpr product and function.J Acquir Immune Defic Syndr 1990, 3:11-18.

44. Balotta C, Lusso P, Crowley R, Gallo RC, Franchini G.: Antisense phosphorothioate oligodeoxynucleotides targeted to the vpr gene inhibit human immunodeficiency virus type 1 replication in primary human macrophages.Journal of virology 1993, 67:4409-4414.

45. Mologni D, Citterio P, Menzaghi B, Zanone Poma B, Riva C, Broggini V, Sinicco A, Milazzo L, Adorni F, Rusconi S, Galli M, Riva A; rHoPeS Group: Vpr and HIV-1 disease progression: R77Q mutation is associated with long-term control of HIV-1 infection in different groups of patients.AIDS 2006, 20:567-574.

46. Cavert W, Webb $\mathrm{CH}$, Balfour HH Jr.: Alterations in the C-terminal region of the HIV-1 accessory gene vpr do not confer clinical advantage to subjects receiving nucleoside antiretroviral therapy. The Journal of infectious disease 2004, 189:2181-2184.

47. Chui C, Cheung PK, Brumme CJ, Mo T, Brumme ZL, Montaner JS, Badley AD, Harrigan PR: HIV VprR77Q mutation does not influence clinical response of individuals initiating highly active antiretroviral therapy.AIDS research and human retroviruses 2006, 22:615-618.

48. Bunn PA, Jr., Foss FM: T-cell lymphoma cell lines (HUT102 and HUT78) established at the National Cancer Institute: history and importance to understanding the biology, clinical features, and therapy of cutaneous T-cell lymphomas (CTCL) and adult T-cell leukemia-lymphomas (ATLL).J Cell Biochem Supp/ 1996, 24:12-23.

49. Fadok VA, Voelker DR, Campbell PA, Cohen JJ, Bratton DL, Henson PM: Exposure of phosphatidylserine on the surface of apoptotic lymphocytes triggers specific recognition and removal by macrophages.J Immunol 1992, 148:2207-2216.

50. Venkatachari NJ, Majumder B, Ayyavoo V: Human immunodeficiency virus (HIV) type 1 Vpr induces differential regulation of $\mathrm{T}$ cell costimulatory molecules: direct effect of $\mathrm{Vpr}$ on $\mathrm{T}$ cell activation and immune function. Virology 2007, 358:347-356.

51. Thierry S, Marechal V, Rosenzwajg M, Sabbah M, Redeuilh G, Nicolas JC, Gozlan J: Cell cycle arrest in G2 induces human immunodeficiency virus type 1 transcriptional activation through histone acetylation and recruitment of CBP, NF-kappaB, and c-Jun to the long terminal repeat promoter.J Virol 2004, 78:12198-12206.

52. Selliah N, Finkel TH: Biochemical mechanisms of HIV induced T cell apoptosis. Cell Death Differ 2001, 8:127-136.

53. Perfettini JL, Castedo M, Roumier T, Andreau K, Nardacci R, Piacentini M, Kroemer G: Mechanisms of apoptosis induction by the HIV-1 envelope.Cell Death Differ 2005, 12 Suppl 1:916-923.

54. Netchiporouk E, Gantchev J, Tsang M, Thibault P, Watters AK, Hughes JM, Ghazawi FM, Woetmann A, Odum N, Sasseville D, Litvinov IV: Analysis of CTCL cell lines reveals important differences between mycosis fungoides/Sezary syndrome vs. HTLV-1(+) leukemic cell lines. Oncotarget 2017, 8:9598195998. 
55. Stewart SA, Poon B, Jowett JB, Xie Y, Chen IS: Lentiviral delivery of HIV-1 Vpr protein induces apoptosis in transformed cells.Proc Natl Acad Sci U S A 1999, 96:12039-12043.

56. Doitsh G, Galloway NL, Geng X, Yang Z, Monroe KM, Zepeda O, Hunt PW, Hatano H, Sowinski S, Munoz-Arias I, Greene WC: Cell death by pyroptosis drives CD4 T-cell depletion in HIV-1 infection.Nature 2014, 505:509-514.

57. Galloway NL, Doitsh G, Monroe KM, Yang Z, Munoz-Arias I, Levy DN, Greene WC: Cell-to-Cell Transmission of HIV-1 Is Required to Trigger Pyroptotic Death of Lymphoid-Tissue-Derived CD4 T Cells.Cell Rep 2015, 12:1555-1563.

58. Munoz-Arias I, Doitsh G, Yang Z, Sowinski S, Ruelas D, Greene WC: Blood-Derived CD4 T Cells Naturally Resist Pyroptosis during Abortive HIV-1 Infection.Cell Host Microbe 2015, 18:463-470.

59. Lenardo MJ, Angleman SB, Bounkeua V, Dimas J, Duvall MG, Graubard MB, Hornung F, Selkirk MC, Speirs CK, Trageser C, et al: Cytopathic killing of peripheral blood CD4(+) T lymphocytes by human immunodeficiency virus type 1 appears necrotic rather than apoptotic and does not require env.J Virol 2002, 76:5082-5093.

60. Bolton DL, Hahn BI, Park EA, Lehnhoff LL, Hornung F, Lenardo MJ: Death of CD4(+) T-cell lines caused by human immunodeficiency virus type 1 does not depend on caspases or apoptosis.J Virol 2002, 76:5094-5107.

61. Pan T, Wu S, He X, Luo H, Zhang Y, Fan M, Geng G, Ruiz VC, Zhang J, Mills L, et al: Necroptosis takes place in human immunodeficiency virus type-1 (HIV-1)-infected CD4+ T lymphocytes.PLoS One 2014, 9:e93944.

62. Paiardini M, Muller-Trutwin M: HIV-associated chronic immune activation./mmunol Rev 2013, 254:78101.

63. Rock KL, Kono H: The inflammatory response to cell death.Annu Rev Pathol 2008, 3:99-126.

64. Yang Y, Jiang G, Zhang P, Fan J: Programmed cell death and its role in inflammation.Mil Med Res 2015, 2:12.

65. Cann AJ, Zack JA, Go AS, Arrigo SJ, Koyanagi Y, Green PL, Koyanagi Y, Pang S, Chen IS: Human immunodeficiency virus type 1 T-cell tropism is determined by events prior to provirus formation. $J$ Virol 1990, 64:4735-4742.

66. Haltiner M, Kempe T, Tjian R: A novel strategy for constructing clustered point mutations.Nucleic Acids Res 1985, 13:1015-1025.

67. Koyanagi Y, Miles S, Mitsuyasu RT, Merrill JE, Vinters HV, Chen IS: Dual infection of the central nervous system by AIDS viruses with distinct cellular tropisms.Science 1987, 236:819-822.

68. Morner A, Bjorndal A, Albert J, Kewalramani VN, Littman DR, Inoue R, Thorstensson R, Fenyo EM, Bjorling E: Primary human immunodeficiency virus type 2 (HIV-2) isolates, like HIV-1 isolates, frequently use CCR5 but show promiscuity in coreceptor usage.J Virol 1999, 73:2343-2349.

69. http://www.aidsreagent.org/pdf_images/3685_003.pdf. 
70. Purdue C: 2007. J. Paul Robinson for Purdue University Cytometry Laboratories, West Lafayette, IN, 47907-2057, ISBN 978-1-890473-10-5: MMK Holdings, Ltd. Publisher; Volume 10.

71. Trahtemberg U, Atallah M, Krispin A, Verbovetski I, Mevorach D: Calcium, leukocyte cell death and the use of annexin V: fatal encounters.Apoptosis 2007, 12:1769-1780.

72. Rouet F, Ekouevi DK, Chaix ML, Burgard M, Inwoley A, Tony TD, Danel C, Anglaret X, Leroy V, Msellati $P$, et al: Transfer and evaluation of an automated, low-cost real-time reverse transcription-PCR test for diagnosis and monitoring of human immunodeficiency virus type 1 infection in a West African resource-limited setting.J Clin Microbiol 2005, 43:2709-2717.

\section{Figures}


A)

\begin{tabular}{llllll} 
& \multicolumn{1}{c}{$\begin{array}{c}1 \\
\text { WT }\end{array}$} & ATG & AGG & 77 & 96 \\
\cline { 2 - 5 } Net & Arg & AGA & \\
\cline { 2 - 5 } Null & GTG & & & \\
\cline { 2 - 5 } & Val & & &
\end{tabular}
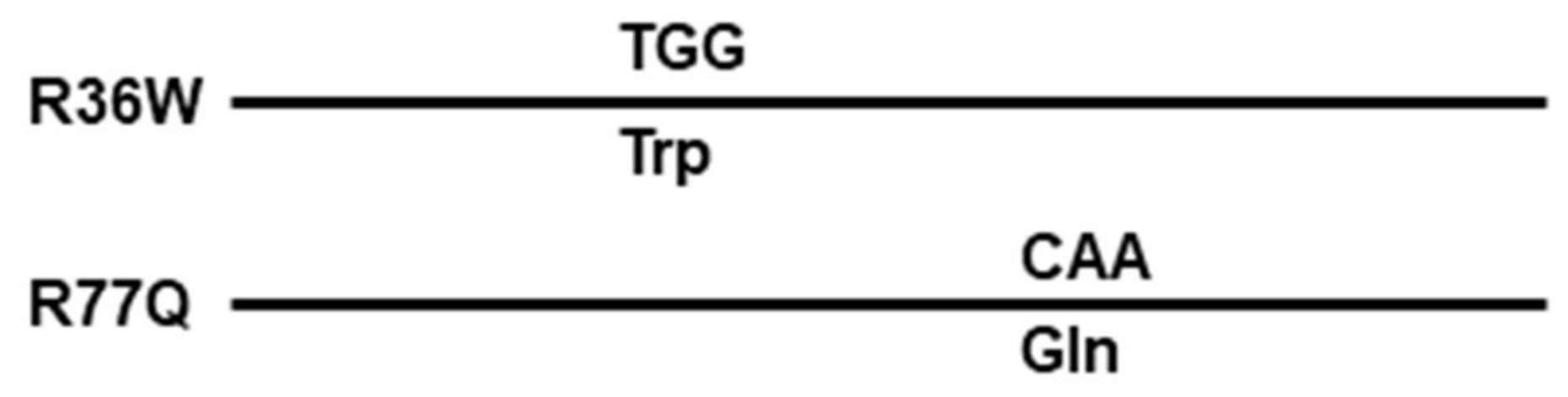

B)

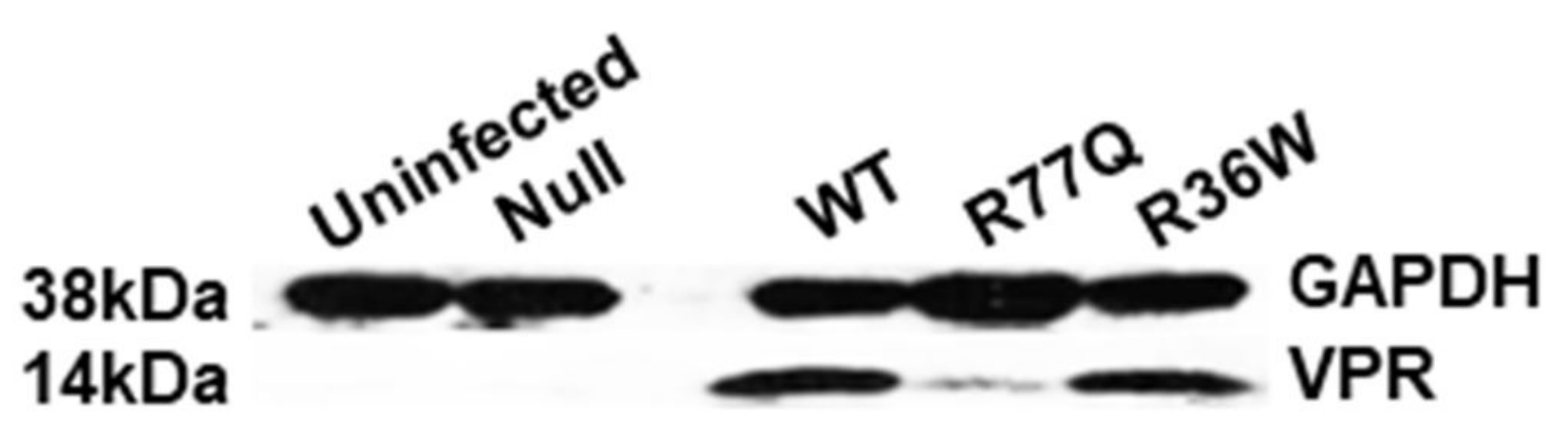

Figure 1

Differences in nucleotide and amino acid sequences between vpr mutants and confirmation of proper gene expression by immunoblot. (A) Sequence comparison of the mutations produced by site-directed mutagenesis in NL4-3 HIV vpr. (B) Immunoblotting confirmed Vpr expression in HUT78 cells infected with WT, R36W, or R77Q while no Vpr expression was detected in the null mutant or in uninfected cells. GAPDH was used as a loading control. 
A)

\begin{tabular}{llllll} 
& \multicolumn{1}{c}{$\begin{array}{c}1 \\
\text { WT }\end{array}$} & ATG & AGG & 77 & 96 \\
\cline { 2 - 5 } Net & Arg & AGA & \\
\cline { 2 - 5 } Null & GTG & & & \\
\cline { 2 - 5 } & Val & & &
\end{tabular}
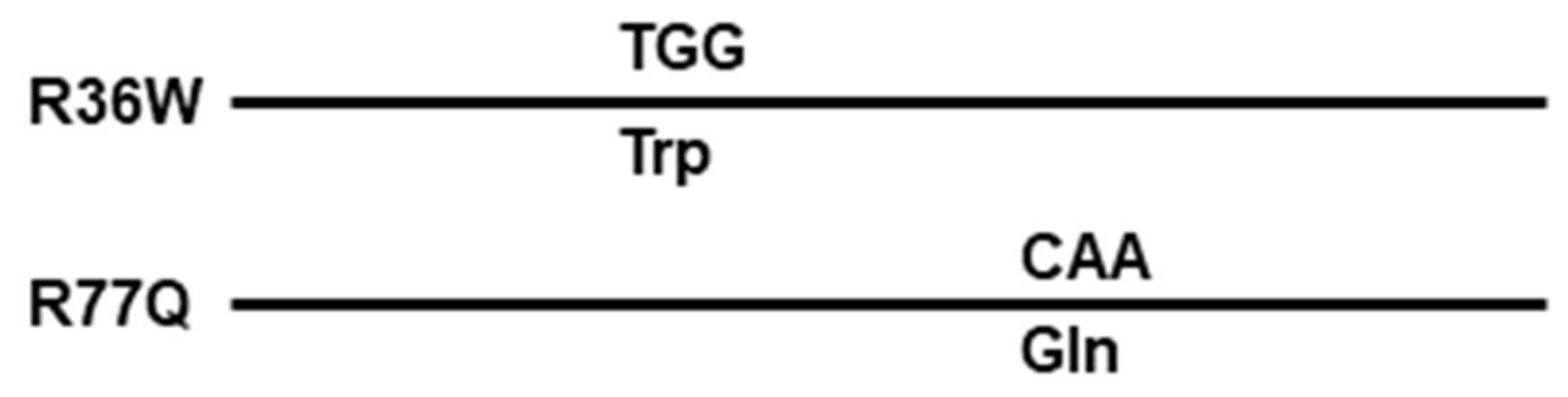

B)

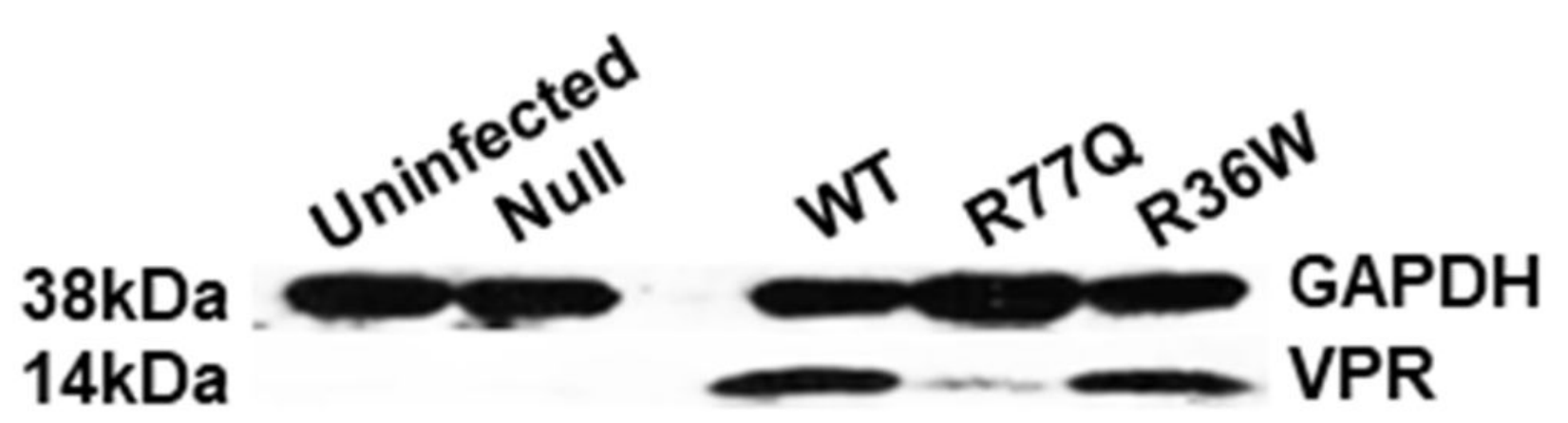

Figure 1

Differences in nucleotide and amino acid sequences between vpr mutants and confirmation of proper gene expression by immunoblot. (A) Sequence comparison of the mutations produced by site-directed mutagenesis in NL4-3 HIV vpr. (B) Immunoblotting confirmed Vpr expression in HUT78 cells infected with WT, R36W, or R77Q while no Vpr expression was detected in the null mutant or in uninfected cells. GAPDH was used as a loading control. 


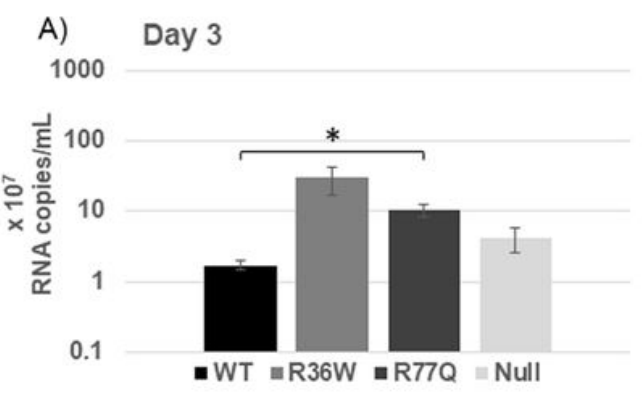

B)

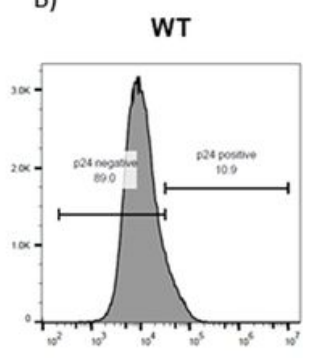

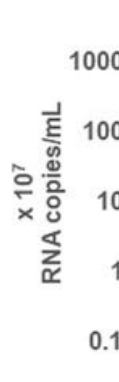

R36W

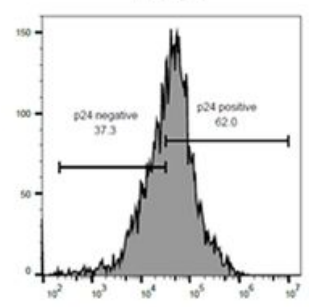

0.1
Day 5
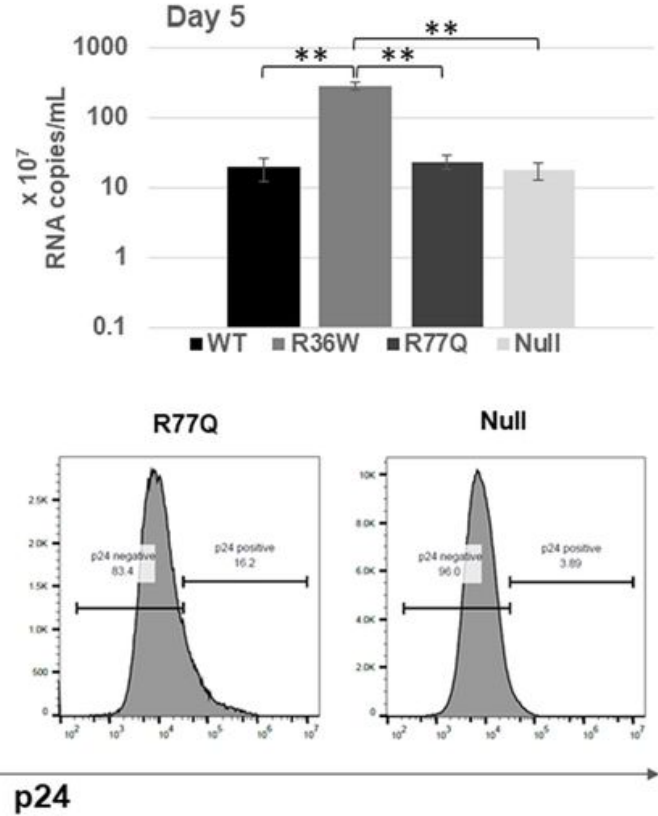

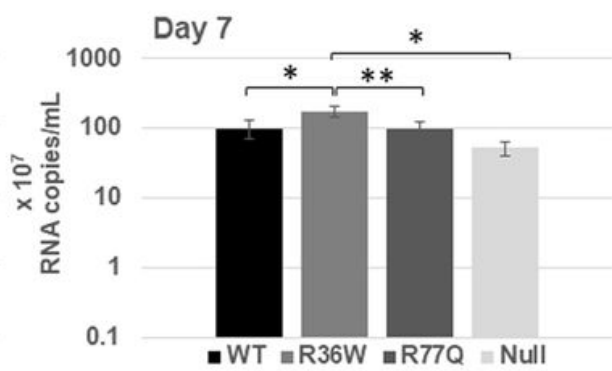

C)

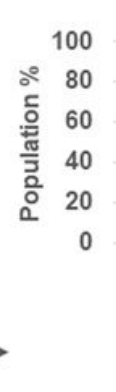

p24 positive

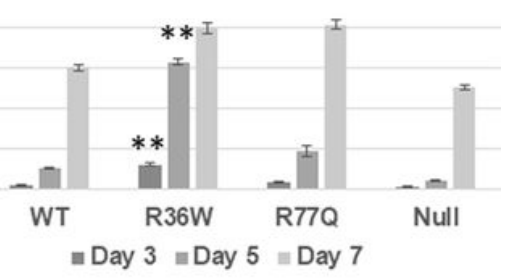

Figure 2

The R36W mutant shows enhanced viral replication. R36W, R77Q or null HIV Vpr mutants, or WT NL4-3 were used to infect HUT78 cells at MOI 0.01. At 3, 5 and 7 dpi supernatants were analyzed for viral load and cells were analyzed for $\mathrm{p} 24$ expression. A) Quantification of viral replication was determined through Q-RT-PCR. B) Assessment of p24+ populations via flow cytometry. Histograms show representative results from $7 \mathrm{dpi}$. In $\mathrm{B}$, asterisks only show statistical differences between R36W compared to all other samples. The data are representative of 3 independent experiments and error bars indicate Standard Error (SE). * $p$-value $<0.05$, ** $p$-value $<0.01$. See supplementary material S1 and S2 for complete statistical analysis.

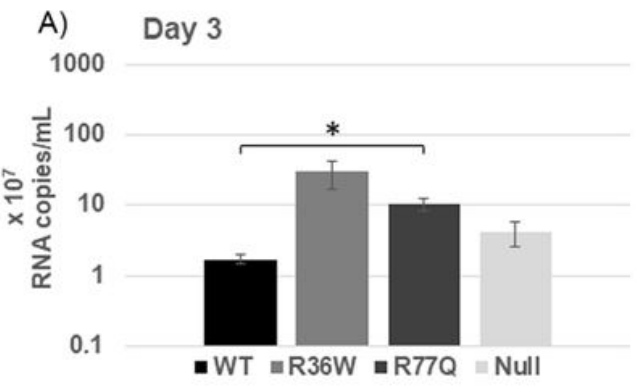

B)

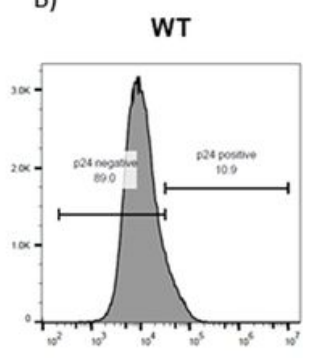

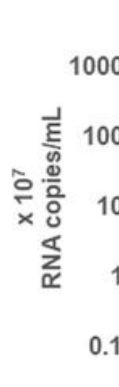

R36W

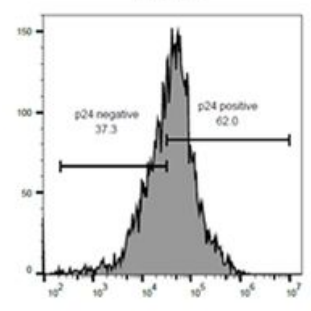

Day 5
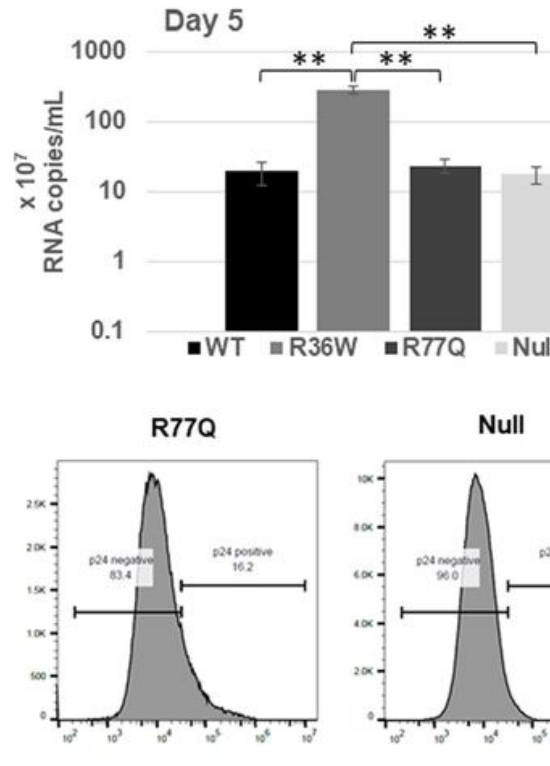

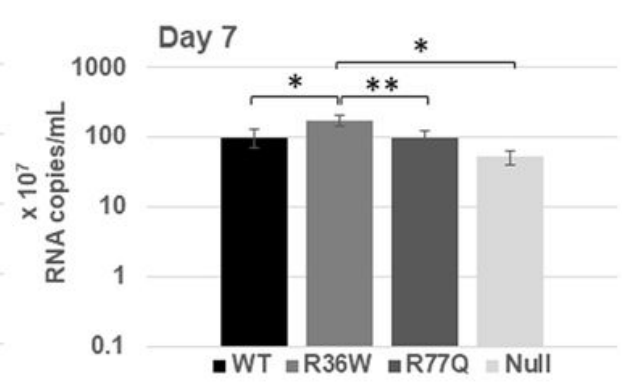

C)

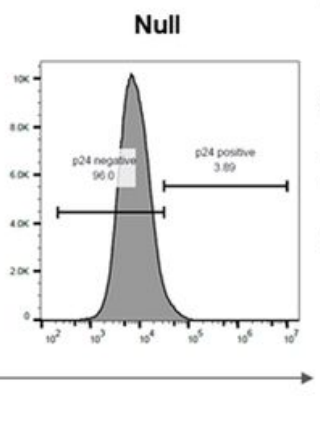

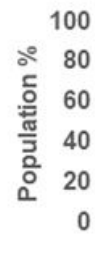

p24 positive

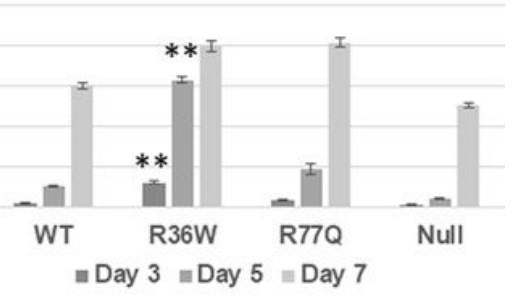


Figure 2

The R36W mutant shows enhanced viral replication. R36W, R77Q or null HIV Vpr mutants, or WT NL4-3 were used to infect HUT78 cells at $\mathrm{MOI} 0.01$. At 3,5 and $7 \mathrm{dpi}$ supernatants were analyzed for viral load and cells were analyzed for $\mathrm{p} 24$ expression. A) Quantification of viral replication was determined through Q-RT-PCR. B) Assessment of p24+ populations via flow cytometry. Histograms show representative results from $7 \mathrm{dpi}$. In $\mathrm{B}$, asterisks only show statistical differences between R36W compared to all other samples. The data are representative of 3 independent experiments and error bars indicate Standard Error (SE). * $p$-value $<0.05,{ }^{* *} p$-value $<0.01$. See supplementary material $S 1$ and $S 2$ for complete statistical analysis.

A)

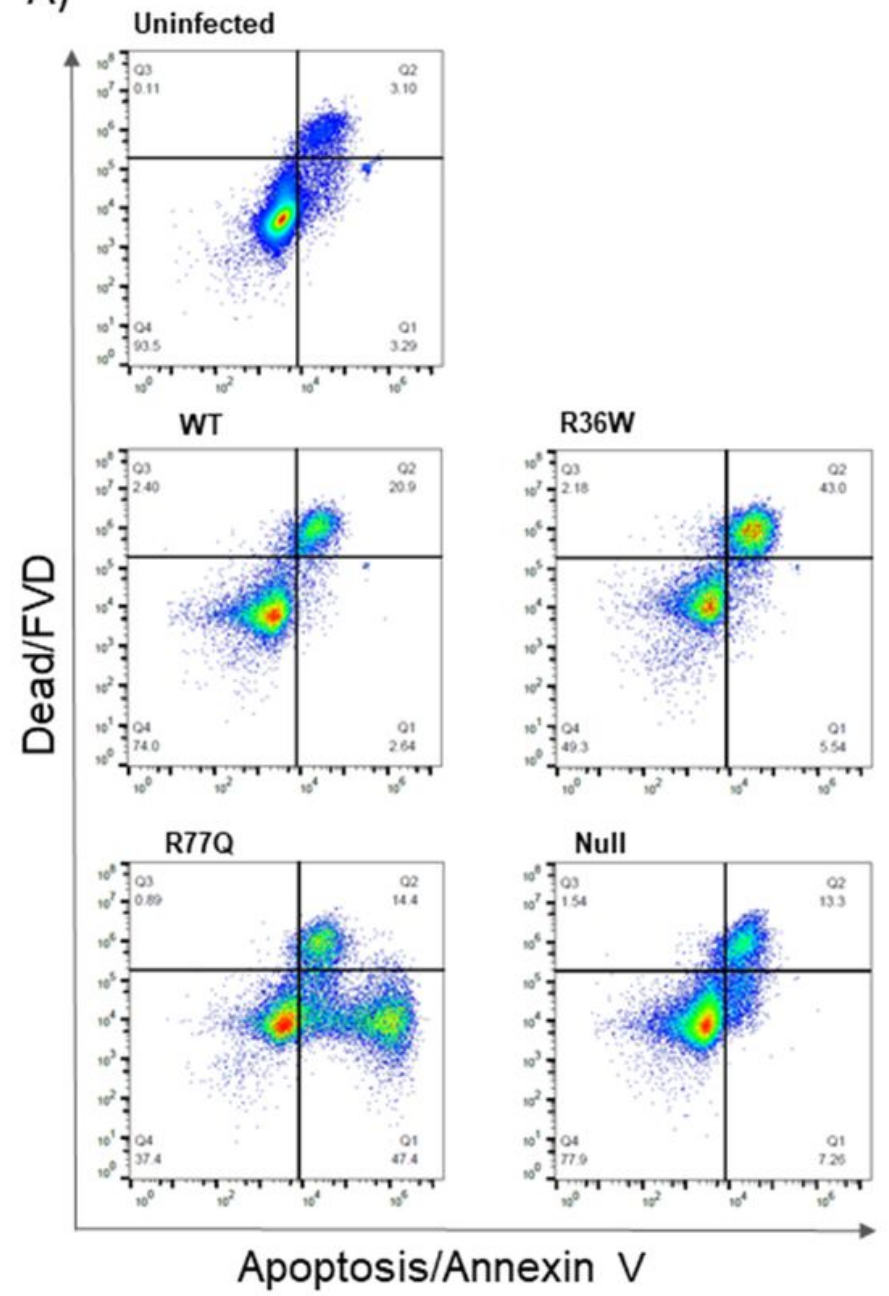

B)

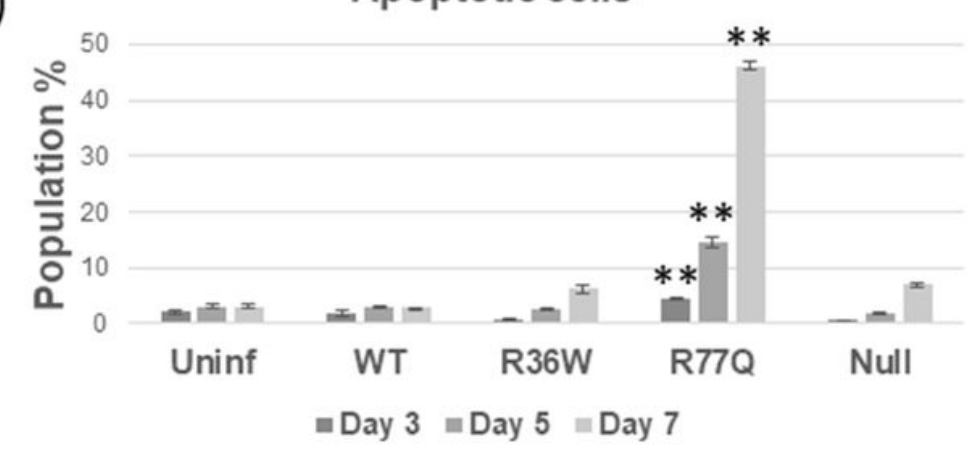

C)

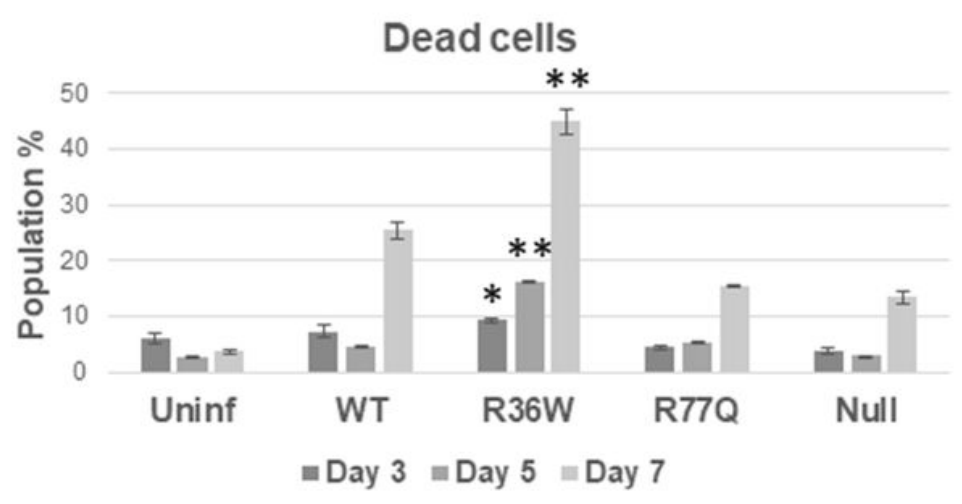

\section{Figure 3}

R36W and R77Q Vpr mutants trigger different death pathways. R36W, R77Q or null HIV Vpr mutants, or WT NL4-3 were used to infect HUT78 cells at MOI 0.01. Cell samples were analyzed at 3, 5 and $7 \mathrm{dpi}$. Apoptosis was detected by Annexin V staining and fixable viability dye (FVD) was used to detect dead cells via penetration of the dye across a porous plasma membrane. Thus, all FVD+ cells are expected to 
also bind Annexin $\mathrm{V}$, but not due to phosphatidylserine flipping to the outer membrane. A) Representative dot plots from samples collected on day 7 pi. B) Apoptotic cells (positive for Annexin V only). C) Dead cells (all cells positive for FVD). Asterisks show statistical differences between R36W (panels C) or R77Q (panels B) and all the other samples. Data are representative of 3 independent experiments and error bars indicate SE. * $p$-value $<0.05$, ** $p$-value $<0.01$. See supplementary material S4 for complete statistical analysis.

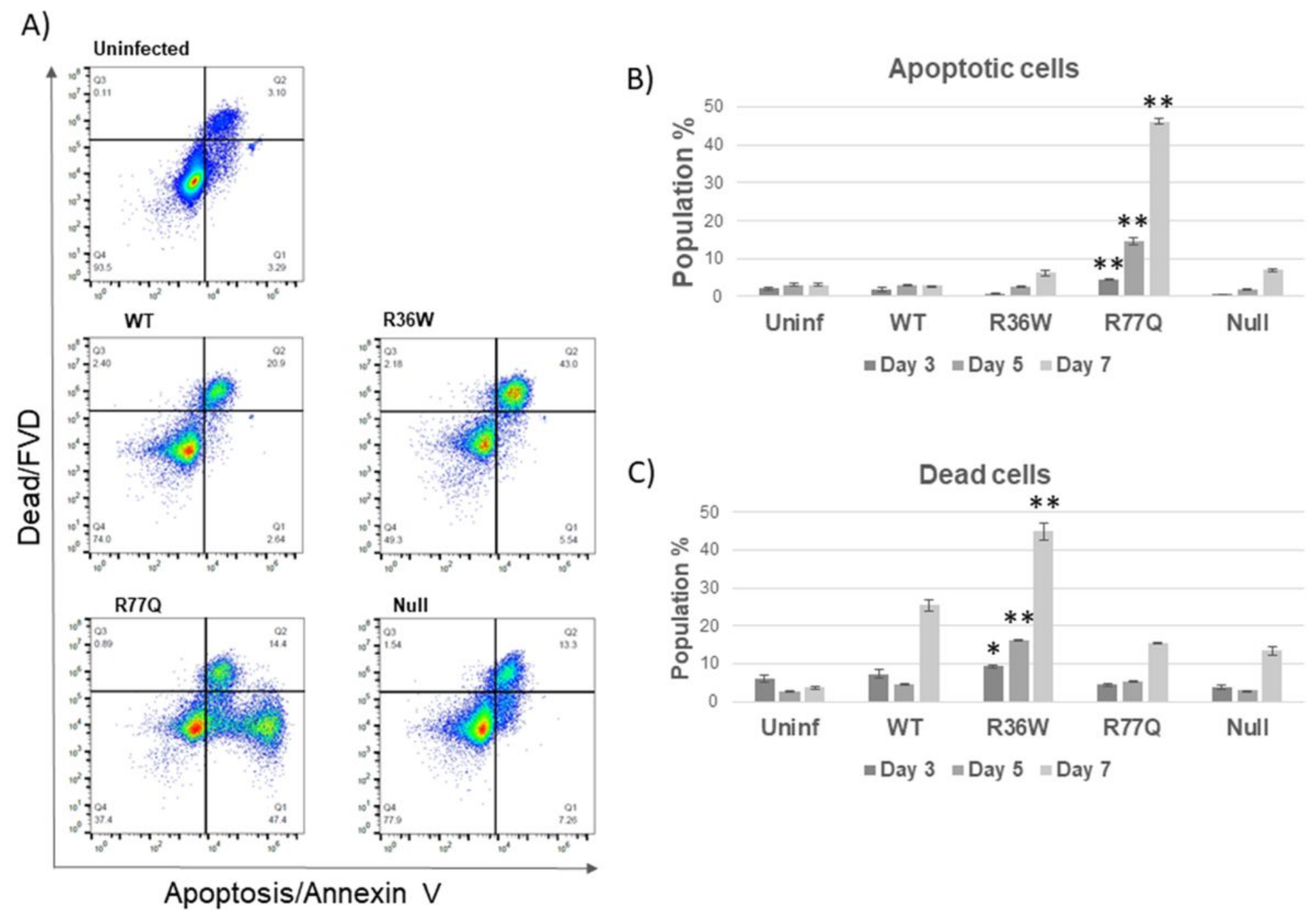

\section{Figure 3}

R36W and R77Q Vpr mutants trigger different death pathways. R36W, R77Q or null HIV Vpr mutants, or WT NL4-3 were used to infect HUT78 cells at MOI 0.01. Cell samples were analyzed at 3, 5 and $7 \mathrm{dpi}$. Apoptosis was detected by Annexin V staining and fixable viability dye (FVD) was used to detect dead cells via penetration of the dye across a porous plasma membrane. Thus, all FVD+ cells are expected to also bind Annexin $\mathrm{V}$, but not due to phosphatidylserine flipping to the outer membrane. A) Representative dot plots from samples collected on day 7 pi. B) Apoptotic cells (positive for Annexin V only). C) Dead cells (all cells positive for FVD). Asterisks show statistical differences between R36W (panels C) or R77Q (panels B) and all the other samples. Data are representative of 3 independent experiments and error bars 
indicate SE. * $p$-value $<0.05,{ }^{* \star} p$-value $<0.01$. See supplementary material $S 4$ for complete statistical analysis.

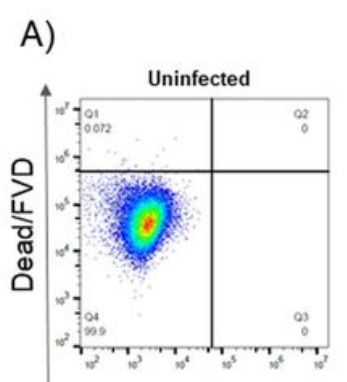

B)

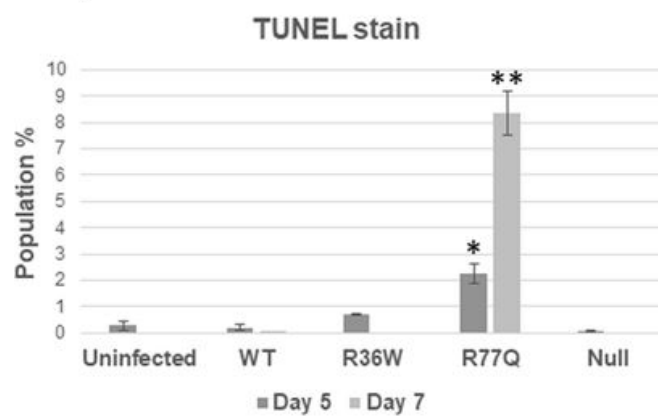

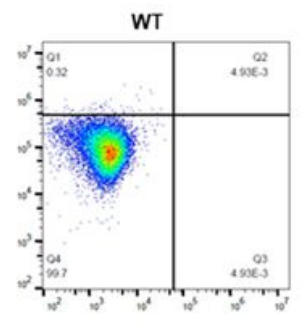

C)

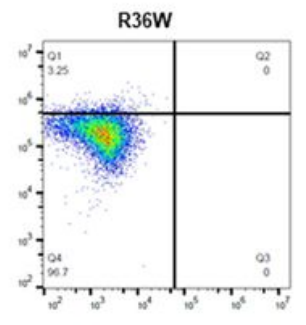

Apoptosis/TUNEL

Day 5 Annexin V vs TUNEL

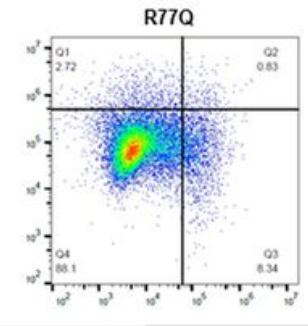

D)

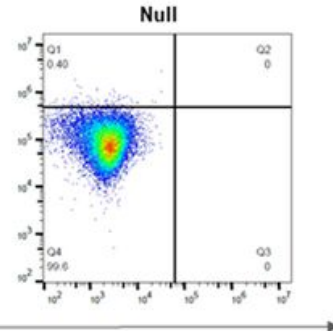

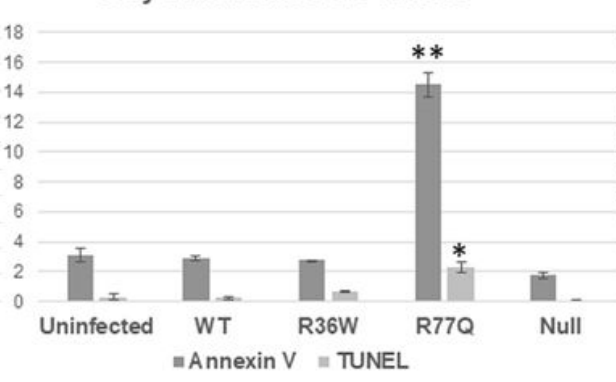

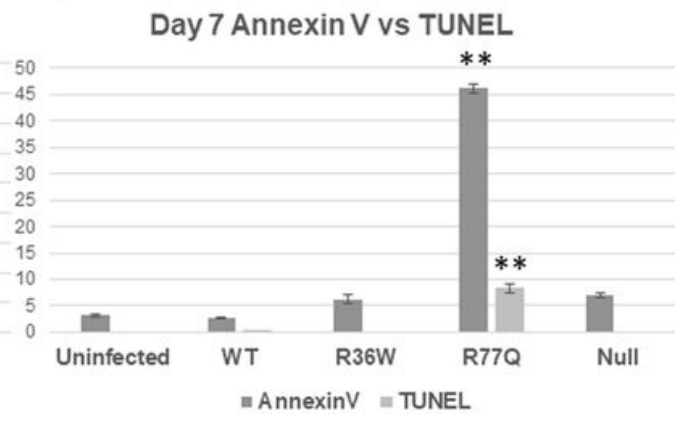

\section{Figure 4}

R77Q enhanced apoptosis confirmed by TUNEL stain. R36W, R77Q or null HIV Vpr mutants, or WT NL4-3 were used to infect HUT78 cells at MOI 0.01. Cell samples were analyzed at 5 and $7 \mathrm{dpi}$. A) Representative dot plots from day 7 pi. B) Bar graph representing the TUNEL single-positive cells of each sample. C) Bar graphs comparing apoptosis results obtained through TUNEL and Annexin V experiments on day 5 and 7. Asterisks show statistical differences between R77Q and all the other samples. Data are representative of 3 independent experiments and error bars indicate SE. * $p$-value $<0.05$, ** $p$-value $<0.01$. See supplementary material S5 for complete statistical analysis. 
A)

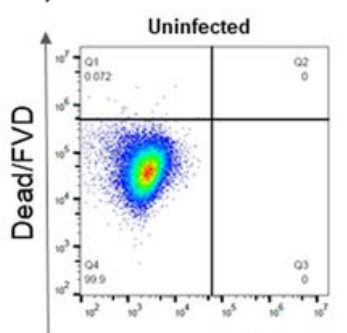

B)

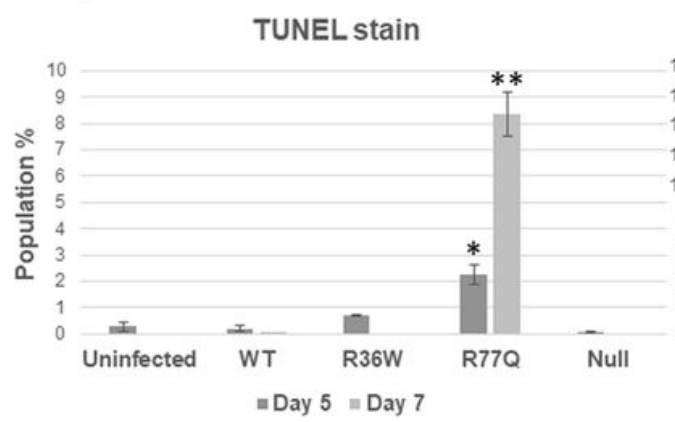

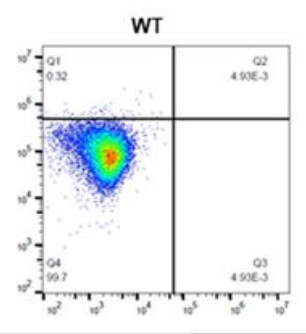

C)

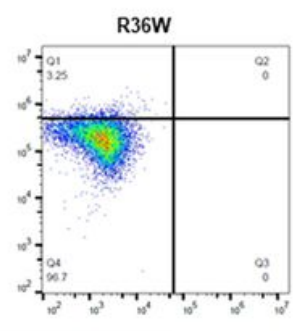

Apoptosis/TUNEL

Day 5 Annexin V vs TUNEL

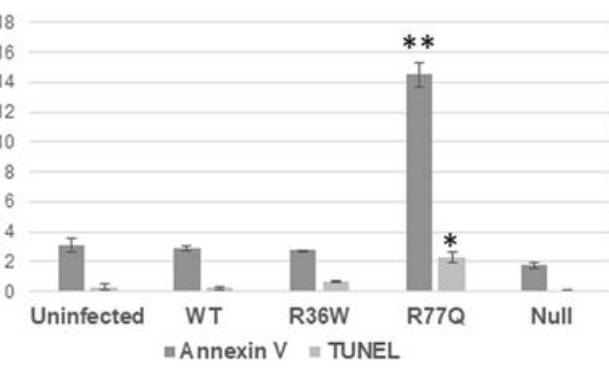

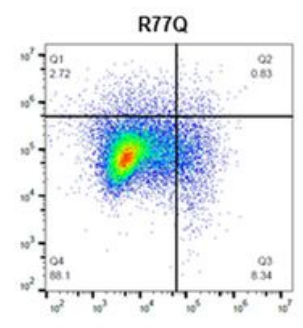

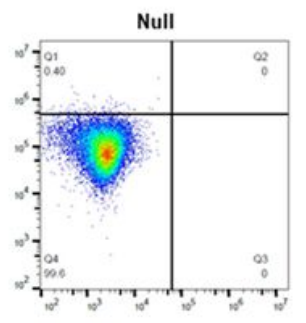

D)

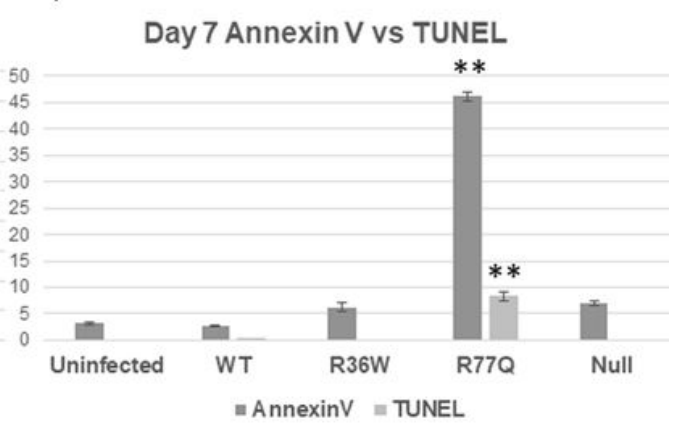

\section{Figure 4}

R77Q enhanced apoptosis confirmed by TUNEL stain. R36W, R77Q or null HIV Vpr mutants, or WT NL4-3 were used to infect HUT78 cells at MOI 0.01. Cell samples were analyzed at 5 and $7 \mathrm{dpi}$. A)

Representative dot plots from day 7 pi. B) Bar graph representing the TUNEL single-positive cells of each sample. C) Bar graphs comparing apoptosis results obtained through TUNEL and Annexin V experiments on day 5 and 7. Asterisks show statistical differences between R77Q and all the other samples. Data are representative of 3 independent experiments and error bars indicate $S E$. * $p$-value $<0.05$, ${ }^{\star *} p$-value $<0.01$. See supplementary material S5 for complete statistical analysis.
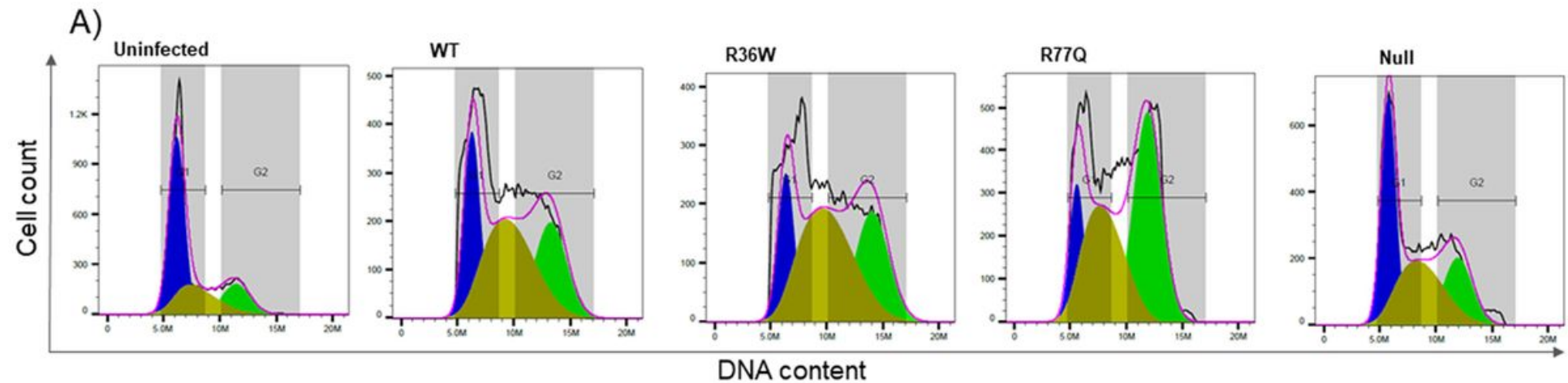

B)

Cells in $\mathrm{G} 2$ phase

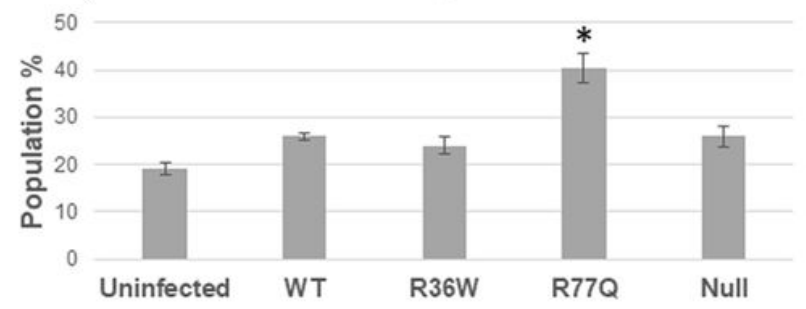




\section{Figure 5}

R77Q strongly enhances cell cycle arrest. R36W, R77Q or null HIV Vpr mutants, or WT NL4-3 were used to infect HUT78 cells at MOI 0.1. Cell cultures were gated on p24+ cells for cell cycle analysis. A) Representative histograms from day 7 pi. B) Percentage of p24+ cells in G2 phase. The asterisk shows a statistical difference between R77Q and all other samples. Data are representative of 3 independent experiments and error bars indicate SE. * p-value $<0.05$. See supplementary material S6 for complete statistical analysis.
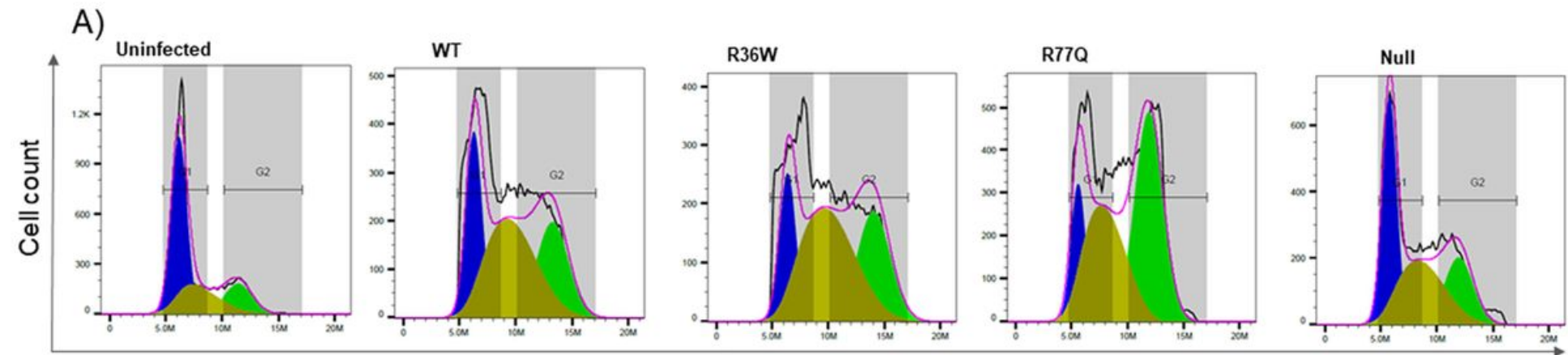

DNA content

B)

Cells in $\mathrm{G} 2$ phase

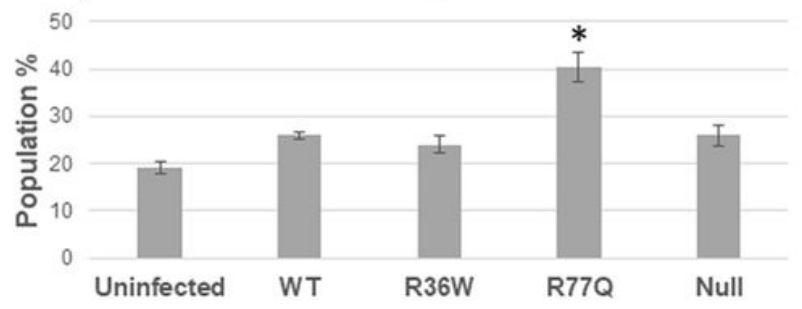

\section{Figure 5}

R77Q strongly enhances cell cycle arrest. R36W, R77Q or null HIV Vpr mutants, or WT NL4-3 were used to infect HUT78 cells at MOI 0.1. Cell cultures were gated on p24+ cells for cell cycle analysis. A) Representative histograms from day 7 pi. B) Percentage of p24+ cells in G2 phase. The asterisk shows a statistical difference between R77Q and all other samples. Data are representative of 3 independent experiments and error bars indicate SE. * p-value $<0.05$. See supplementary material S6 for complete statistical analysis.

\section{Supplementary Files}

This is a list of supplementary files associated with this preprint. Click to download.

- SupplementaryDataSets.xlsx

- SupplementaryDataSets.xlsx 